\title{
Analog Mars Rover Service as a Robotic Hardware and Team Building Platform
}

\author{
Sebastian Meszyński ${ }^{1,2}$, Mateusz Józefowicz ${ }^{2}$
}

\begin{abstract}
Magma White is an analog Mars rover platform created by ABM SE and offered to the developers of scientific equipment built for space exploration missions, who want to test their devices at low- and mid- Technology Readiness Levels in demanding conditions of desert, Alpine and polar regions or artificial environments. The rover offers a remote access to the payload through the Magma White mission control system. The paper summarizes the background of the analog solution. It covers universal interfacing setup and issues related to the team and technological partners, who supply elements of the payloads. Two analog missions provide a case study: Dachstein 2012, when "WISDOM" ground penetrating radar for Exomars was tested onboard Magma White, and Morocco 2013, with "L.I.F.E." payload and complete remote access from Europe.
\end{abstract}

Index Terms-ABM SPACE EDUCATION, Mars Analog Rover, EXOMARS, MAGMA WHITE

\section{INTRODUCTION}

ABM Space Education sp. z o.o. (ABM SE) was established in Poland basing on expertise and human resources of student robotics teams of Mars Society's University Rover Challenge (URC) in Utah. Mars Society Polska - an NGO supporting participation of Poland in international space programs aided the startup. Up till today 11 Polish URC teams have been initiated by these activities, originating from 7 Polish universities. Rover teams included Skarabeusz (2009), Magma (2010), Magma2, Scorpio, Copernicus (2011), Scorpio2 (2012), Hero, Copernicus 2013, Hyperion, SKNL "Legendary" Rover Team, Scorpio3 (2013). ABM SE develops a non-competition, utility versions configured as analog Mars rovers, basing directly on the best solutions and specialists from the competition designs (including the URC

Manuscript received November 29, 2031.

First Author is with the Department of Informatics, Faculty of Physics, Astronomy and Informatics, Nicolaus Copernicus University, Grudziądzka 5, 87-100 Torun, Poland, ABM Space Education, (sebcio@ fizyka.umk.pl)

Second Author, ABM Space Education, Prosta 5/2, 87-100 Toruń, Poland, (mateusz.jozefowicz@abmspace.com) winning designs). The company has developed a design line of $40 \mathrm{~cm}$ edu-toy rovers for education market and a $1 \mathrm{~m}$ long Magma White rover configured as an analog testing platform for third-party equipment. This line is scoped as a specialized service for high-tech market, especially for developers of instrumentation for planetary exploration and for innovative space and non-space solutions. The line is accompanied by logistics mechanism, allowing organization of remote operations in numerous special environments on Earth, including Mars analogs and other areas, such as polar, desert, mountain or urban. Apart from direct tests and feedback, the service offers also general demonstration, technology transfer platform, PR and direct marketing possibilities. The current activity zone includes: Poland, USA and most of EU countries, both in terms of attracting the payloads and presenting the results. ABM SE aims at public and private scientific institutions, private space sector and space agency programs. ABM SE's design has the optional features of "the new generation of Mars rovers", being capable of directly supporting analog astronaut exploration activities.

\section{A. Mobile robotics in planetary analog research Review Stage}

Analog studies and analog technological solutions have been widely used by space agencies [16] and companies, as an important stage of development of missions, plans and designs. In the past they were not, however, regarded as an independent scientific discipline. It was not accompanied by sharing the results in a form of scientific publications and making it widely available to community. Just recently such trend has proved useful both for scientific and small-industrial communities, and for large entities.

Prominent examples of analog studies and selected sites, both community and institutional include: Mars Desert Research Station, Utah, USA, FMARS on Devon Island, Canada (both operated by an NGO - The Mars Society), Haughton-Mars Project, Devon Island, Canada (NASA) [13], Pavilion Lake Research Project, British Columbia (NASA and Canadian Space Agency), McMurdo Antarctic Station tests (NASA) [19], Concordia Antarctic Station tests (ESA), Mars 500 Experiment (ESA, Roskosmos and numerous international partners), AMASE-Svalbard analog missions (NASA, ESA 
and community), D-RATS, Arizona USA (NASA), NEEMO underwater habitat, Florida (NASA), PolAres, Rio Tinto, Spain/Dachstein Alpine caves/Morroco Erfoud (NGO Austrian Space Forum). Sites such as Atacama [21], [6] or Gobi deserts are being used and examined as good Mars analogs. There are also numerous studies focusing on environmental analogies for astrobiology research, including specific extremophile habitats, lakes, craters, volcanic areas. Further research is being conducted in artificial indoor and outdoor facilities, such as NASA ARC "Roverscape", JSC Rock Yard, JPL Mars Yard, CNES Mars Yard [11]. Most of the mentioned programs included test of robotic platforms, usually analog exploration and supporting robots.

Finally one should mention also competitions focusing on space analog tasks, such as NASA Lunabotic Mining Competition, Google Lunar X Prize (stimulating analog studies), NASA Centennial Challenges or Mars Society's University Rover Challenge, that are directly related to development of planetary exploration rovers.

It should be stated, that programs run by large entities and by NGOs/communities have several differences. Furthermore, the community programs are becoming a very attractive form of analog research. It can be assumed, that these open programs stimulate development of small enterprises willing to enter the space market or to specialize in cost-efficient space solutions. New players, without background of wellestablished, dedicated funding programs can benefit from this opportunity [3]. The significance of analog research is reflected in the European $7^{\text {th }}$ Framework Program [7], proving a demand and potentially a market for this type of activity. The open analog programs feature: low cost of research, volunteering work, efficient media mechanism, involvement of non-space players as sponsors and partners, lack of costly bureaucratic and procurement processes and procedures (as opposed to the research performed by large entities), creative freedom (as opposed to complicated and rather strict content selection procedures at large entities), enforcing of rationalization caused by low research budgets. This last feature proves to be very interesting, as it can directly lead to innovation, competitiveness and allows to perform research in times of financial cuts. These features have been also the foundation of ABM SE and Polish URC rovers. The designs have proved to be not only competitive, but also reliable due to their simplicity and easy operation.

Open analog research provides abundance of data, including recording and systematization of even very basic, simple operational and usage observations and experiments. These data are generally available as scientific data, in major part on the Internet, as mission reports, and can be used also by larger entities. It can be assumed, that these data are especially attractive for the industry, since performing of such simple, but often lengthy activities within regular structures of industrial or public employment is economically unjustifiable. So open analog research proves to be a reasonable way of gaining these data and recording potentially critical observations, that might save missions, programs and budgets.

In some areas of activities analog research provides very good simulation of actual planetary conditions, while in some areas it is only an approximation. Still a merger of realistic simulation and approximation creates a potential for inclusion of all possible elements of a planetary mission. Each of the studies focuses on different aspects of such a mission, while the others are approximated. For mechanical and other solutions for exploration rovers, analog research proves to be quite effective. It allows to implement proper knowledge for actual planetary robotics in the area of structures, control systems, procedures and communication architecture. The applicable knowledge ranges from simple observations [2] to technical compendia for flight hardware [9], [1]. Due to the Earth mass it can be assumed, that structure efficiently working on Earth, will likely work efficiently on Mars, Moon or other bodies less massive than the Earth. A proper algorithm for calculation of mass-to-power ratios for planetary robotics is a tool that puts analog research one significant step further.

\section{B. ABM SE analog Mars rover hardware and software}

Magma White is a mobile robotic platform developed by ABM SE as analog Mars rover. [Fig. 1]. It is a $100 \mathrm{~cm} \mathrm{long,}$ $90 \mathrm{~cm}$ wide, $35 \mathrm{~kg}$ rover made of plastics capable of withstanding standard ambient temperatures in most of Earth's environments. The rover has 6 wheels with independent motors, non-steered, with 6 independent beams, secured with lightweight, temperature-resistant flexible bands. The deck allows installation of various accessories, including the main camera mast, main antenna mast and the 3-stage robotic arm, constituting the standard equipment. This equipment can be replaced by special payloads. Main computer system is located in the central trunk, isolated from external conditions. Rover runs on off-the-shelf batteries, allowing operation of more than 6 hours. Communication is realized over standard Internet protocols: WiFi $5 \mathrm{GHz}$, and $2,4 \mathrm{GHz}$ frequency for diagnostics. Control software and interface are dedicated for Windows PC and Android smartphone. This solution allows easy operation and fast introduction for potential users, as well as easy integration with existing infrastructures in any location. Range of rover operation depends on the type of antenna used. The rover electronics are arranged in a modular fashion. It allows time-effective reconfiguration of the platform for each expedition, payload and experiment. The electronic modules are easily accessible and can be quickly replaced in case of potential failure or according to mission schedule requirement. General functional blocks include: power, computer, motor driver, communication, camera, and additional modules. Voltage generating module works in pulse mode to provide efficient power preservation. Onboard computer controls all execution and input modules. All other modules, such as camera, communication, can be replaced with analogous modules of different type (WiFi, analog radio, BT etc., different types of cameras, sensors, etc.). Power and interface buses with efficient throughput allow flexible adaptation to 
mission requirements. Currently a version 3 control software is used: after the initial version for a single PC, a new more extended version was prepared, together with an Android smartphone control module, and currently completely new software is being created, in a form of local/remote control center for the rover and the payloads, capable of simulating various space-specific features, such as time delays and communication breakdowns.

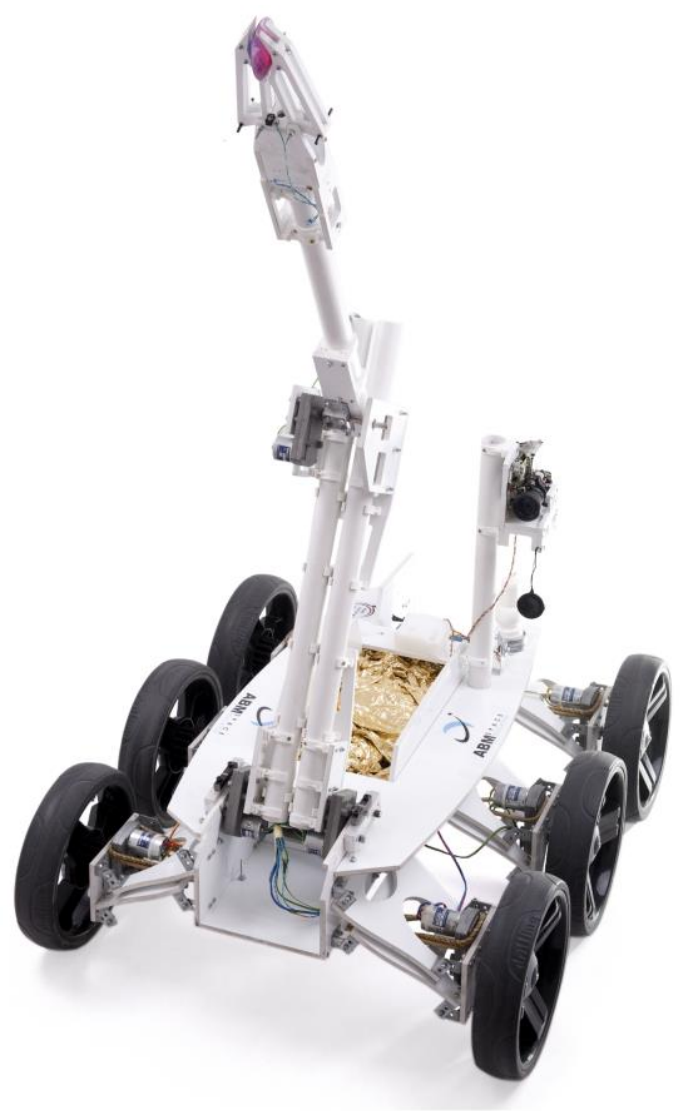

Fig. 1 Magma White standard setup

This general characteristics result from experiences gained during the University Rover Challenge [12] and during later tests. Various types of suspensions have been tested, as well as RF communication for commands and video, with various results. The hull is a structure resulting from the adopted suspension model and it was designed by Wojciech Głażewski, who also designed two URC competition rovers from the Magma series. Such characteristics allow operation of the rover in: rocky and sandy desert terrain in temperatures up to $40^{\circ} \mathrm{C}$ (tested; higher possible), simulated regolith, with slopes up to 40 degrees, on rock fragments several centimeters large. The rover can reach average speed of $5 \mathrm{~km} / \mathrm{h}$ in easy desert terrain. Also ice and snow surfaces have been tested. Ambient temperatures below zero Celsius do not cause any problems. The rover performs very well on pure clean ice and crushed ice. It is capable of making a smooth, easy traverse and does not slid while turning or stopping. Slow speeds are recommended. Deep snow is difficult to cross; further tests are required. The rover has also been successfully tested in urban, pavement, grassy, wood terrains of Central European type. The purpose of this rover setup is to provide potential to carry equipment and experiments developed for planetary exploration missions, such as: arms, sampling tools, optical and laser meters, geophysical devices with antennas or electrodes, drills, scoops, penetrators, various cameras, as well as mechanical add-ons and alternative or auxiliary power sources. The flexible architecture, both of the structure and the electronics, allows connection and remote operation of any kind of scientific devices up to $20 \mathrm{~kg}$ of total weight. Analog's modularity allows continuous development of the design, from simulated and replacement modules and materials, towards architectures and solutions for spaceflight.

\section{Significance of team building}

Development of competent team is as important, as the development of the hardware/software, especially for a small company. Creative pool and growing experience are the most important resources of a team, and they are not easily replaceable, especially in a niche type of activity. Spacefocused education in Poland is officially present only at the Warsaw University of Technology, and a few universities also teach the necessary skills, but without shaping of the graduates' identity, as space sector professionals. In terms of establishing a stable team a specific approach had to be adopted. It required several years of preparatory activities and a strategic plan. Initial activities were based on Mars Society Polska, that actively initiated, encouraged and supported student URC teams. From those teams competent management and engineering staff has emerged, and the self-confidence was further leveraged by competition successes. Currently these specialists constitute the core team of ABM SE, and new specialists are being recruited from ever emerging Polish URC rover teams. The company invites the best technical URC solutions to be incorporated in the professional version. The company also recruits non-URC staff directly, emphasizing the opportunity to take part in analog space missions. Most of them are fist job employees, with background in technical physics, mechanics, electronics and IT. This approach allows to shape a dedicated team of space sector professionals, who offer original, generic technical solutions. The team is young and creative, willing to use very modern tools with the potential for space applications. Also the URC success story, and some additional projects, such as ABM SE's Virtual Mars Rover system in a form of video game, attract many promising professionals. Game and simulation systems are believed to be a very efficient hardware and team building tool, as confirmed by experience and opinions [8].

Analog space missions prove to be attractive and appealing not only to the direct participants-employees. Since these missions are both attractive and accessible to media, as expeditions performed in medially exotic or space-like and reasonably possible to reach environments, they constitute a great education and outreach tool [18]. In case of projects that allow additional funding or support, this tool can be used for direct stimulation of the space sector. It engages non-space 
parties, especially technological companies, as sponsors and providers of non-space solutions needed for simulation. These parties join because of outreach and advertising potential of the mission. As a result these parties can eventually become interested in direct engagement into higher-profile missions, whether analog or space-oriented. ABM SE case is a good example of such industrial team building. The process started with a distributor of electronic components for the URC rover designs (TME), who later joined the ABM SE's analog mission in Dachstein, together with a distributor of electromechanical components (Archimedes). Both companies joined also the ABM SE's Morocco 2013 mission. With this supply and development environment it is much easier to select proper analog design, and the company itself is able to provide the partners with detailed feedback related to performance of their components in relevant environments.

\section{Dachstein 2012 Mars analog mission}

Dachstein 2012 Mars analog Mission was organized by the Austrian Space Forum (OEWF), with participation of 12 international scientific teams [10]. It took place between $27^{\text {th }}$ April and $1^{\text {st }}$ May 2012, in Dachstein Giant Ice Caves in the Alps, providing a good Mars regolith analog, potential Martian cave analog and area of testing the of equipment on clean ice (horizontal and sloped ice surfaces). Some additional challenges were important, such as protecting the rover against high humidity (up to $100 \%$ ), low temperatures (from $+2{ }^{\circ} \mathrm{C}$ to $2^{\circ} \mathrm{C}$ inside the cave and lower temperatures outside the cave), providing proper grip on ice, and especially limiting of the interaction with the natural conditions inside (of) the cave. The cave is a protected habitat. Limiting of human supervision was the first exercise for the team, emphasizing the need to develop a supervision-free and highly sterile solution. In practice the exercise was not very successful, but allowed to notice this problem. ABM SE's team had two goals. One was the first field test of the new Magma White electronics and control architecture, with remote control from the Mission Control Center located in a cable car station below the caves. Development works before the mission and recording of parameters during the mission focused on gathering the data for analysis of intelligent power management [14], [17]. Runs on clean ice, on rocky, sloped area, as well as overnight hibernation tests were performed inside the caves. The most complex activity included controlling the rover remotely and performing a joined task with the Antipodes experiment: an analog EVA space suit tester has interacted with the rover on the test site, with parallel communication with a scientific team in Wellington, New Zealand. The task was performed in a satisfactory way, considering its procedural complexity. For the ABM SE team it was the first occasion to participate in a global mission control procedure. The second goal for ABM SE was a joint operation with Wisdom ground penetrating radar (GPR) team [4]. The device is being developed for the Exomars rover, and Magma White provided an opportunity to achieve sample GPR results from automated runs on even ice surface. $25 \mathrm{~cm}$ movement increments were adapted, and
Wisdom hardware was synchronized with Magma White driving system, performing a sequence: $25 \mathrm{~cm}$ move measurement - processing. The sequence was preprogrammed, so the operator had only to initiate it and then decide on the end point, when the rover approached a dangerous ice fall. $25 \mathrm{~cm}$ increments were controlled by a dedicated encoder. The adapted algorithm is presented [Algorithm 1]. Basing on observations, a $4 \mathrm{~cm}$ precision margin was not exceed for each move. Wisdom module was installed in the front of the rover, after removal of the standard robotic arm [Fig. 2]. Antennas were easily accommodated, maintaining a constant, proper distance from the probed surface. Additionally, GPR main module and an auxiliary laptop were mounted on the main installation guides on top of the rover deck. The whole joint experiment had been prepared for several months in advance. Magma White team had a mockup fixing plate prepared according to Wisdom team instructions. The plate was installed in ABM SE's workshop and trial runs with $9 \mathrm{~kg}$ load (equal to the Wisdom hardware at that time) were conducted in Poland to ensure smooth operation in Austria. Wisdom and Magma White were integrated in Dachstein very fast and without the need of structural modifications. 2,4 GHz communication channel had to be switched off to eliminate GPR interference. Wisdom team managed to capture satisfactory sample profiles of ice layers with the use of the rover. Joined activity was presented at the 2012 International Workshop for Planetary Missions in Greenbelt Maryland [5]. PRoVisG [15] system for generation of 3D surrounding reconstruction was an additional payload. Its markers were installed in selected points of the cave and onboard of the moving rover. The idea was to reconstruct movements of the rover in a virtual 3D environment, and later correlate it with Wisdom measurements.

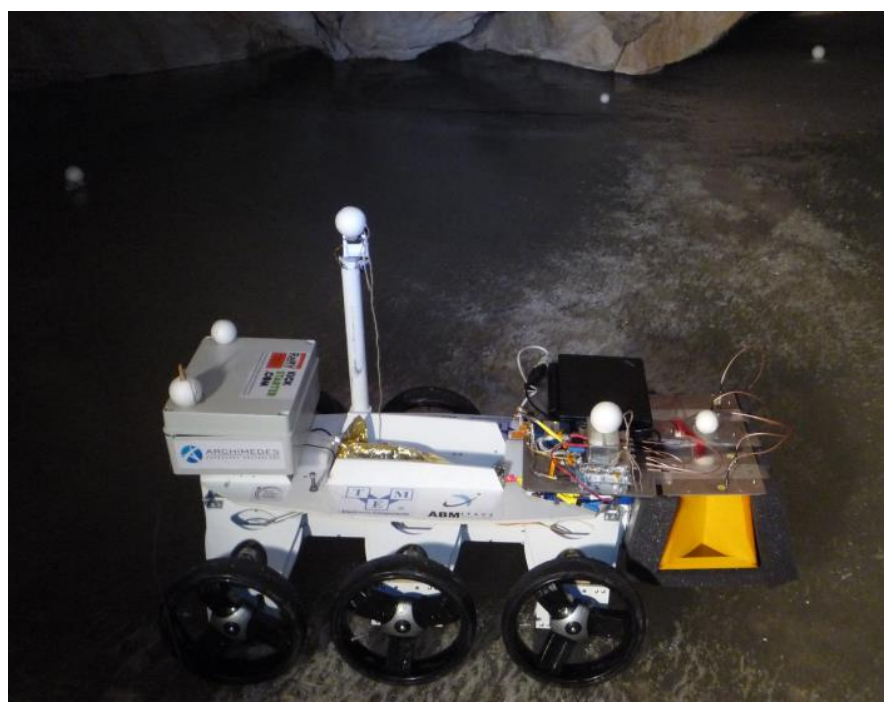

Fig. 2 Magma White with WISDOM payload and PRoVisG markers during the Dachstein 2012 analog Mars mission 


\section{E. Morocco 2013 Mars analog mission}

Mars analog simulated Mission Morocco 2013 was also organized by the OEWF, between $1^{\text {st }}$ and $28^{\text {th }}$ of February 2013, in the Moroccan Sahara desert near Erfoud. In December 2012 a two days preparatory dress rehearsal was also performed in Innsbruck, with a dozen of international teams present. Comparing to Dachstein 2012, Morocco 2013 was a more realistic simulation. The terrain simulated wellknown features of Mars surface. For the purposes of Magma White runs it was divided into three categories: easy (flat, hardened and loose sand surface with fine gravels), moderate (loose sand and diversified gravel size, dry bushes present, periodical shallow stream beds, relatively poor Mars analog), hard (rocky hill slopes with inclination up to $50 \%$, diversified rock sizes). Operations were performed during the day, with temperatures reaching $+35^{\circ} \mathrm{C}$. The rover was stored for the night in a non-heated tent, while the temperatures dropped to $4^{\circ} \mathrm{C}$. Additional difficulties included presence of fine dust and (of) strong winds every 5-6 days. The Mission Support Center (MSC) was located in Innsbruck. The desert camp simulated a habitat of a field (landing) crew and remained in constant communication with the MSC, over the Internet. The experiments were either taken to the Sahara directly by the Austrian field crew or first installed by the experiment teams during the first week of February, and then left under the supervision of the Austrian field crew. These experiments were later controlled from the field base, MSC or directly from experiments home sites (such as Toruń, Poland in case of ABM SE). During the simulation OEWF was to supervise all experiments, with the use of the field crew of 8 , including 2 EVA spacesuit simulators, and the scheduled communication windows. ABM SE did send a team of 3 to Morocco to install Magma White rover in the base camp and perform the communication test with the Innsbruck MSC and the ABM SE headquarters in Torun. The team left after 5 days of nonsimulation mode activities. ABM SE's first simulated sessions were performed from Innsbruck MSC, and the remaining sessions from Torun, through the MSC. All telemetry, video and control data were available in all three locations. The base camp did have a fair Internet connection from a local provider, and at a later stage a broadband satellite link was installed in the desert, improving the communication. Magma White did connect to the base camp network via $5 \mathrm{GHz}$ connection. Two basic mission operation modes were employed: simulation ( $\operatorname{sim}$ ) and non-sim. The sim mode did apply a 10 minutes delay on all communication with the field crew and 10 minutes delay for the crew to communicate with the MSC. It was the basic mode used every day by the OEWF for most of the activities. For non-sim activities a natural signal, video and command delay resulting from the network and satellite band and link quality was present. On the field crew side ABM SE's experiments required basically switching on and off (of) the rover and charging (of) the batteries.
L.I.F.E detector [20] was the main payload for Magma White in Morocco 2013 [Fig. 3]. L.I.F.E. (Laser-induced fluorescent experiment) is a $4 \mathrm{~kg}$ laser/optical module in an aluminum housing. Laser light from the tip has to be projected on a probed surface (preferably rock), where microbial life is suspected. The tip had to approach samples quite closely (about $1 \mathrm{~cm}$ distance was assumed), and proper flexibility of its movement had to be maintained. Algorithms for aiding of instrument positioning were adapted. One algorithm [Algorithm 2] controlled tilting of the instrument platform to an optimum position, where a proximity sensor on the instrument tip recorded the closest tip position without moving (of) the whole rover. Another algorithm [Algorithm 3] combined Algorithm 1 of the rover movement and Algorithm 2 of the instrument tilt control, allowing almost autonomous approach of the sample. This semi-autonomous method with the use of algorithms still requires proper calibration.

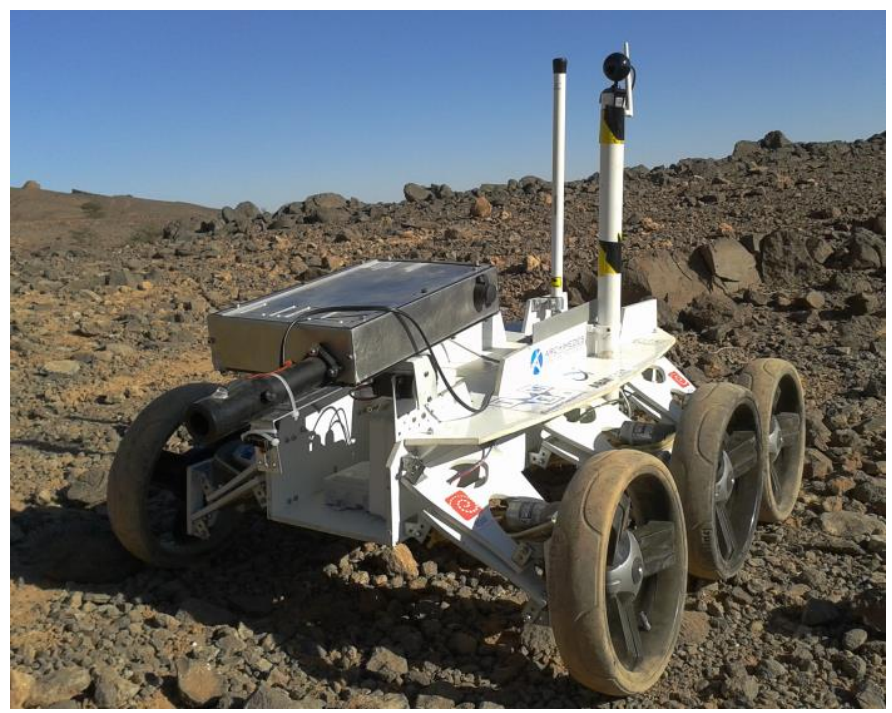

Fig. 3 Magma White with L.I.F.E. payload during the Morocco 2013 analog Mars mission

L.I.F.E. instrument was installed in the front part of the rover (after removing the standard robotic arm), on two servos allowing its tilting from vertical position (- 90 degrees in relation to the rover plane) to servo-off traveling position ( +20 degrees in relation to the rover plane). This arrangement allows flexible approaching of probed samples. It does not allow movement to the sides, so the whole rover has to be turned. Additionally control laptop, connected directly to the rover's system through an Ethernet cable, was installed on the installation guides on the rover's deck. Working with L.I.F.E. revealed several elements that have to be corrected, including implementation of a solution allowing shading (of) the sample from ambient light, and possible mass reduction, at least for the analog tests, since manipulating of a solid one-piece instrument consumes a lot of rover's power resources. For future payloads a modular approach is suggested, where only the manipulated head is placed on moving parts, and as much 
of other instrument systems as possible are placed in another fixed module. This approach is, however, difficult to achieve with and optical device, such as L.I.F.E., so limiting of the housing mass could be a good solution here. No Earth vs. Mars gravity mass-to-power calculations were performed for optimization of power consumption by the experiment this time.

During the mission the following main tests were performed.

- Regolith slope runs, run 1, non-sim, terrain: hard. Suspension tests on rocky slopes. Local control. Status: success.

- Rover follow, run 1, non-sim, terrain: hard. Exercise with EVA suit tester closely following the rover's path, rover as a safety scout. Local control. Status: success.

- L.I.F.E. local test, run 11/2, additional workshop run, nonsim. First approaches of sample rock set in the workshop conditions. Implementation of autonomous instrument tip control. Status: success.

- L.I.F.E. payload runs, runs 1, 2 non-sim, run 5 sim, terrain: easy. Approaches of rock samples in the field, on a preselected rock, sampling trials, test of handling the payload by the rover, power consumption tests. Status: moderate success, sampling method requires additional development.

- Remote control test from Torun with local supervision, runs 2, 3, non-sim, terrain: easy to moderate. Establishing of overseas control link, the rover controlled from ABM SE headquarters, supervised locally by ABM SE team in Sahara. Trial runs. Status: success.

- Presentation to the Moroccan Minister of Science and Higher Education, run 4, non-sim, terrain: easy. Operated by ABM SE team from Innsbruck. With local non-ABM SE supervision. The Minister present at the field camp in Sahara.

- Remote control test from Innsbruck, with local non-ABM $S E$ supervision, run 5, sim, terrain: easy to moderate. ABM SE team (has) moved to Innsbruck and all activities of the rover were supervised by the OEWF field team. Control commands and crew messages were sent by ABM SE team from MSC. Status: success.

- Remote diagnostics with local non-ABM SE team, run 6, sim and non-sim, workshop run. Performed by ABM SE team from Innsbruck. After losing (of) communication with the rover it was moved to the workshop by the field crew and diagnostic procedure was performed, step by step, with and without the field crew, with reestablishing of some vital rover functions. Status: success, no definite cause was stated, but the procedure was efficient and reestablished rover functions. The problem did not appear again till the end of the mission.

- Presentation to ESA delegation to Poland, run 7, non-sim, terrain: easy. Rover operated from Torun, monitored from Warsaw by ABM SE and ESA delegates.

- Remote control test from Toruń, without supervision, run 8 , sim/non-sim, terrain: easy to moderate: ABM SE team (has) left MSC. Control commands were sent from Torun, with MSC monitoring. Field crew participation limited to switching the rover on and off. Status: success.

- Navigation and range test without GPS reference, run 8, sim/non-sim, terrain: easy to moderate. Navigation basing on visual terrain features, analysis for future autonomous software processing. Testing of WiFi coverage in the base camp vicinity. Control from Toruń. Status: success.

- Power source longevity test, run 8 , sim/non sim, terrain: easy to moderate. Free exploration run with L.I.F.E. payload removed. Control from Torun. Status: 6 hours of operation confirmed, more available but not tested.

- Joint run with Hungarian PULI rover, run 9, sim/non sim, terrain: easy. MSC, PULI Mission Control in Hungary and $\mathrm{ABM}$ SE headquarters were involved in running of this activity, together with the supervisory field team. Coordination of several control centers was practiced, operation of two rovers, navigating with visual system and taking photos of each other was practiced. WiFi coverage in the vicinity of the base camp was tested, by comparison of WiFi signal strength on each of the two rovers in the same and different locations. Additionally operation in strong wind conditions, with fine dust being blown onto the rovers, and their systems, including optical, was tested. Status: success.

- EVA suit monitoring, run 10 , sim, terrain: moderate. Test operated from Toruń, in coordination with MSC. Rover monitored EVA suit tester activities during "Delta" experiment. Practicing of coordination of rover actions with suit actions, to provide a mobile supporting, safety and monitoring platform for EVA. Status: success, with remarks related to a requirement of dedicated procedure for joint activity.

- Navigation test, run 11 , sim/non sim, terrain: easy to moderate. Spot tracking device installed on the rover, as additional GPS system. The aim of the test was to teach the driver and the route planning team to correlate quickly data from camera images with a satellite image and to decide on the optimum, safest moves, observe the results, observe the power level. Control from Torun. Status: fair, with slight deviation from the planned route and with loss of Spot signal after 23 track points. Rover was driven to the base without further position updates.

- Component trials and analyses for Archimedes, TME, runs $1,2,3,5,8,9,10,11$ sim and non sim, all terrain types Status: success, valuable data for the partners gathered.

- New software field trials, all runs. Status: success.

- New electronics field trials, all runs. Status: success.

- Dust influence trials, all runs. Status: no adverse effects noted. A simple dust deposition monitoring method failed.

- Prolonged usage trials, all runs. Status: success. Only one failure noted during 11 main runs and additional workshop activities, performed between $1^{\text {st }}-28^{\text {th }} \mathrm{Feb}$, without direct, hands-on access of ABM SE team to the hardware from $7^{\text {th }}$ Feb. The failure was not caused by internal rover's problem, but by a problem on the interface between the rover and local network (probable low bandwidth cause). Sea shipping container and car transport from the coast to Erfoud must be 
considered as additional stressing factors.

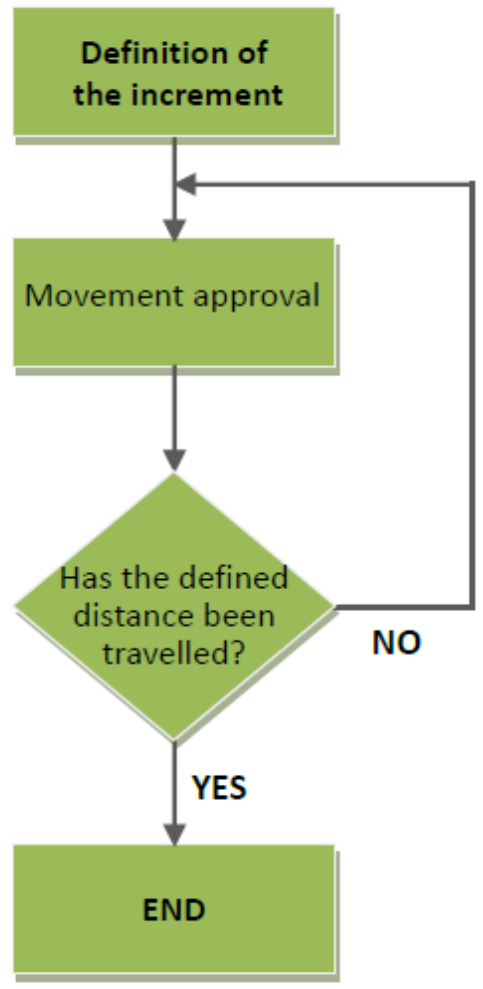

Algorithm 1. Controlling of wheel movement with a defined distance to travel (increments)

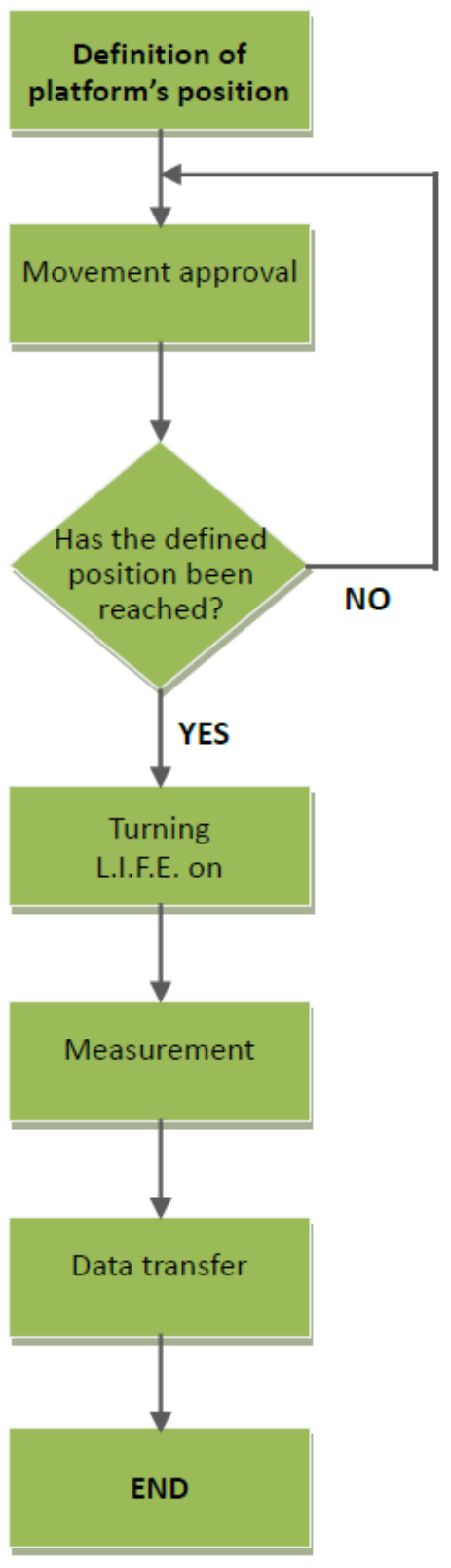

Algorithm 2. Controlling of the movement of L.I.F.E. instrument platform 


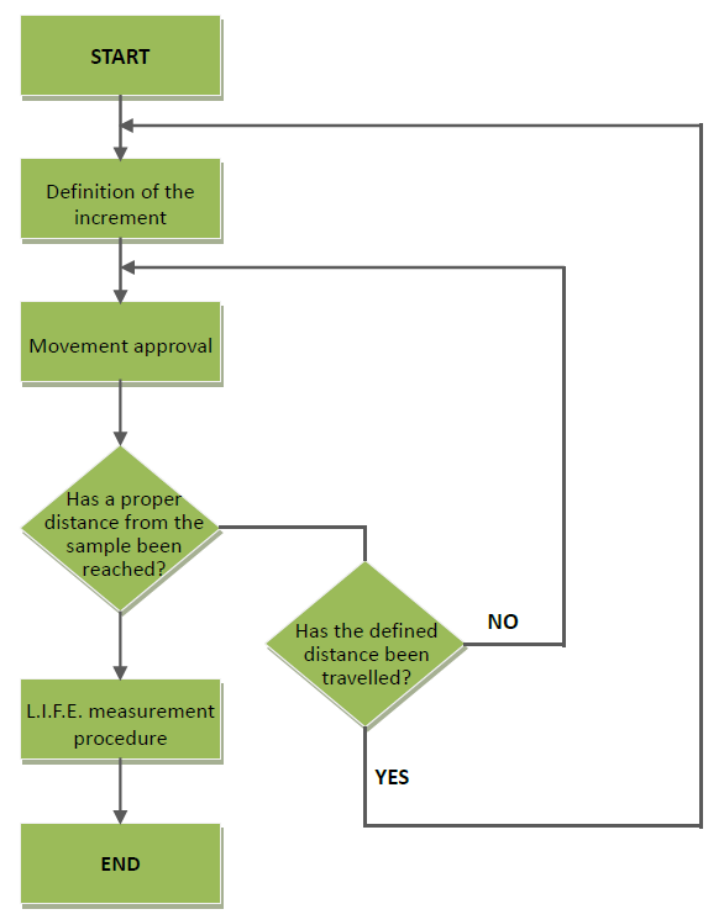

Algorithm 3. Controlling of rover wheel movement with a defined distance between the instrument tip and a sample (sample approach)

\section{CONCLUSION}

The missions described in the paper prove proper development hardware/software and practical team training strategies for creation of a universal planetary exploration analog system, capable of performing tasks in desert, alpine and potentially polar environments. The target platform will constitute a breadboard for higher TRL space and non-space systems. Direct postulates include development of communication system and philosophy, capable of coping with low-bandwidth or communication breakdowns and development of a specific level of autonomy. These postulates call for organizing a High Arctic expedition, where satellite communication limitations are present, requiring a dedicated communication solution, and where components can be tested in even more demanding conditions. The platform and the Arctic mission perspective raise interest among engaged and potential partners. This brings up a postulate to keep developing the basic hardware platform along with highly universal interfaces for third-party payloads. Basing on just a single system consisting of one rover and up to three control centers, the missions engaged a numerous team, with various competences, including technical and scientific ones, in a form of employment and voluntary scientific support. In a wider context, the team included also representatives of industry partners, interested in the offered service. Finally, the missions provide an opportunity to present specific technologies, separately or in a whole package, to the international community, by means of direct presence in the field with a group of international teams, large coverage of international, specialized and popular media and by summarization and publication of the results in reports and scientific literature. It can be stated that contemporary space analog research has the potential of stimulating space industry in the area of planetary robotics, even without being attached to any specific mission or program. It can also attract additional non-space budgets and open door to the space sector for non-space players. The described missions have proved to be a valuable platform for various types of compatible activities. They have been organized by an SME, with a relatively low budget. Also progress from the URC, through the two analog missions, to the planned High Arctic mission has been shown. The main conclusion states, that such a coordinated, progressive effort, involving more and more parties finds justification and should be continued. Financing is the only major limitation for continuation of this program in a similar form. Much better results could be achieved with stabilized funding of the program. Such funding can be achieved by means of a dedicated grant. The conclusion calls for application for such a grant, either to ESA, EC, Polish or other funding schemes.

\section{REFERENCES}

[1] Angelo JA (2006) Robot Spacecraft. Facts On File, Incorporated ISBN-13: 978-0-8160-5773-3, ISBN: 0-8160-5773-7

[2] Blank A, Kamat A, Knowles B, Kobrick RL, Sapp J, Wilson R (2005) Field Testing a Robotic Assistant for Use in Extravehicular Activities. In: Crossman F, Zubrin R (ed) On To Mars 2. Exploring and Settling a New World, Apogee Books Space Series No 55: 217222, Canada

[3] Boros-Olah M, et al (2009) HungaroMars2008: Analog Research in the Education of Planetary Sceince. Lunar and Planetary Institute Science Conference Abstracts. Vol. 40

[4] Ciarletti V, et al (2011) WISDOM GPR designed for shallow and high-resolution sounding of the Martian subsurface. Proceedings of the IEEE 99.5: 824-836.

[5] Ciarletti V, et al (2012) WISDOM a GPR for the ExoMars Rover Mission. LPI Contributions 1683: 1126

[6] Dohm JM, et al (2005) Life in the Atacama-Year 2: Geologic reconnaissance through long-range roving and implications on the search for life. Lunar and Planetary Science XXXVI

[7] European Commission (2012), Work Programme 2013. Cooperation. Theme 9. Space. European Commission C(2012) 4536 of 09 July 2012: 30-31

[8] ESA (2010) Online Game Technology for Space Education and System Analysis, MindArk PE AB

[9] Genta G (2012) Introduction to the Mechanics of Space Robots, Springer Science+Business Media B.V., ISBN 978-94-007-1795-4

[10] Groemer G, et al. (2012) Dachstein Mars Simulation 2012 Mission Report

[11] Josset Jean-Luc (2011) ESTEC-CNES Rover Remote Experiment \# 2 with Pancam, Wisdom and Clupi. ASTRA Workshop $14^{\text {th }}$ April 2011

[12] Józefowicz M, Meszyński S, et al. (2010) Problematyka zawodów University Rover Challenge. Wybrane wytyczne dla robota operującego w warunkach pustynnych, PIAP

[13] Lee P (2002) Mars on Earth: The NASA Haughton-Mars Project. Ad Astra: The Magazine of the National Space Society 14.3

[14] Mei Y, Yung-Hsiang Lu, Y.C. Hu, and C.S.G. Lee (2005) A case study of mobile robot's energy consumption and conservation techniques. In advanced Robotics, ICAR '05. Proceedings, 12th 
International Conference July 2005:492-497

[15] Morley JG, et al (2012) PRoGIS: a web tool to understand \&process Mars rover imagery in a planetary context. $43^{\text {rd }}$ Lunar and Planetary Science Conference

[16] NASA (2013) Analog Missions and Field Tests. Headquarters. http://www.nasa.gov/pdf/541196main_AnalogFactSheet.pdf. Accessed 20 March 2013

[17] Ngo TD, Schioler H (2006) A truly autonomous robotic system through self-maintained energy, ISARC

[18] Raport PR (2010) Raport PR: Podsumowanie i publikacje, Planet PR

[19] Tamppari LK et al (2010) McMurdo Dry Valleys, Antarctica-A Mars Phoenix Mission Analog. $41^{\text {st }}$ Lunar and Planetary Science Conference, March 1-5, 2010, The Woodlands, Texas. LPI Contribution No. 1533, p. 2464

[20] Tilg M, Storrie-Lombardi M, Kohstall C, Trenkwalder A, Psenner R, Sattler B (2011) L.I.F.E.: laser induced fluorescence emission, a non-invasive tool to detect photosynthetic pigments in glacial ecosystems. In: Hoover RB, Davies PCW, Levin GV, Rozanov AY: Instruments, Methods, and Missions for Astrobiology XIV. Proceedings of SPIE 23-25 August 2011, San Diego, California, United States. Washington

[21] Wierzchos J, Carmen A, McKay CP (2006) Endolithic cyanobacteria in halite rocks from the hyperarid core of the Atacama Desert. Astrobiology 6.3: 415-422

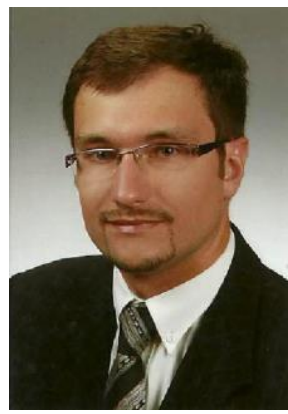

S. Meszyński - is currently a PhD student in the Department of Applied Computer Science and graduate MSc of physics.

$\mathrm{He}$ has experience in the design, construction and commissioning of electronic digital technology devices. He has many years of professional experience at various positions, including managerial positions. He was the leader of electronics and software in all kinds of commercial projects. He takes an active part in the development of Polish space sector, including mobile robotics. He participated in two editions of the University Rover Challenge in the USA. He participated in two international scientific expeditions in testing a mobile robot equipped with a measuring device (e.g. WISDOM, LIFE). He was engaged in research with the simulating of biophysical compartment models and uses of fuzzy logic theory.

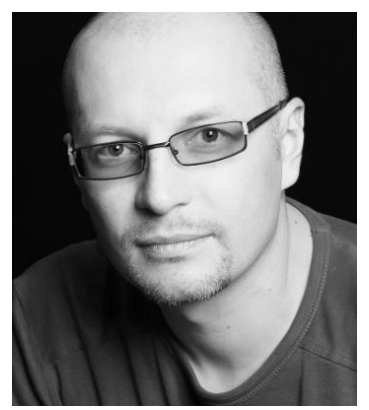

M. Józefowicz - Graduated from archaeology, but shifted towards robotics and space technologies for world heritage preservation and space exploration.

$\mathrm{He}$ is a CEO of ABM Space Education and a co-designer of robot functionalities and field test specialist. He has participated in several analog space rover field campaigns in Utah, Morocco, and Austria. $\mathrm{He}$ is an active consultant for the Polish space industry and administration in the area of bringing together science and business for innovation in the context of Poland's recent ESA membership. He is a Space Educator. 